\title{
Analysis of diaphragmatic movement before and after pulmonary rehabilitation using fluoroscopy imaging in patients with COPD
}

This article was published in the following Dove Press journal:

International Journal of COPD

27 January 2015

Number of times this article has been viewed

\author{
Eun Mi Chun' \\ Soo Jeong $\mathrm{Han}^{2}$ \\ Hitesh $N$ Modi $^{3}$ \\ 'Division of Pulmonary and Critical \\ Care Medicine, Department of \\ Internal Medicine, Seoul, Republic \\ of Korea; ${ }^{2}$ Rehabilitation Medicine, \\ Ewha Womans University School \\ of Medicine, Seoul, Republic of \\ Korea; ${ }^{3}$ Scoliosis Research Institute, \\ Department of Orthopedics, Korea \\ University Guro Hospital, Seoul, \\ Republic of Korea
}

Background: The diaphragm is the principal inspiratory muscle. The purpose of this study was to assess improvements in diaphragmatic movement before and after pulmonary rehabilitation in patients with chronic obstructive pulmonary disease (COPD), using a fluoroscopy-guided chest X-ray.

Patients and methods: Among 117 patients with COPD receiving pulmonary rehabilitation who underwent the initial fluoroscopy-guided chest X-ray and pulmonary function test, 37 of those patients who underwent both initial and follow-up fluoroscopy and pulmonary function tests were enrolled in this study. After hospital education, participants received pulmonary rehabilitation through regular home-based training for at least 3 months by the same physiatrist. We assessed the changes in diaphragm area with fluoroscopy-guided posteroanterior chest X-rays between pre- and postpulmonary rehabilitation. To minimize radiation hazards for subjects, the exposure time for fluoroscopy to take chest X-rays was limited to less than 5 seconds.

Results: There were significant improvements $\left(2,022.8 \pm 1,548.3 \mathrm{~mm}^{2}\right.$ to $3,010.7 \pm 1,495.6 \mathrm{~mm}^{2}$ and 2,382.4 $\pm 1,475.9 \mathrm{~mm}^{2}$ to $3,315.9 \pm 1,883.5 \mathrm{~mm}^{2}$; right side $P=0.001$ and left side $P=0.019$, respectively) in diaphragmatic motion area during full inspiration and expiration in both lungs after pulmonary rehabilitation. Pulmonary function tests showed no statistically significant difference between pre- and postpulmonary rehabilitation.

Conclusion: The study suggests that the strategy to assess diaphragm movement using fluoroscopy is a relatively effective tool for the evaluation of pulmonary rehabilitation in COPD patients in terms of cost and time savings compared with computed tomography or magnetic resonance imaging.

Keywords: COPD, pulmonary rehabilitation, fluoroscopy, diaphragmatic movement

\section{Introduction}

Chronic obstructive pulmonary disease (COPD) will be the fourth leading cause of death by 2020, and remains an important preventable health challenge. ${ }^{1}$ The COPD burden is expected to increase in the coming decades because of the high prevalence of smoking among patients, as well as an aging population. ${ }^{2}$ Pulmonary rehabilitation has emerged as a recommended standard therapy in order to control and alleviate symptoms and optimize functional capacity for COPD patients. ${ }^{3,4}$

In COPD patients, hyperinflation of the lungs decreases the operating length of the diaphragm due to the change in shape and mechanical coupling with the lower rib cage. Patients with COPD have a lower transdiaphragmatic pressure-generating capacity than healthy subjects, which has been ascribed to hyperinflation-induced diaphragm shortening. ${ }^{5}$ The total number of sarcomeres in shortened muscle fiber in COPD patients is lower than in normal controls. ${ }^{6}$ Rochester and Braun ${ }^{7}$ showed a $28 \%$ reduction in diaphragm length 
in patients with COPD at residual volume when compared with normal subjects at their residual volume. The fiber type of diaphragm changes shift to the more fatigue-resistant fibers in severe COPD patients. A proportion of type I fibers in the diaphragm of patients with severe COPD was increased, whereas the proportion of fast-fatiguing fibers (type II) was decreased. ${ }^{8}$ This shift from type II to type I fibers may render the COPD diaphragm more resistant to fatigue. The reduction of maximum force generated by COPD diaphragm fibers was associated with loss of myosin content in these fibers. ${ }^{9}$ Therefore, patients with COPD may have inspiratory muscle weakness, which may contribute to dyspnea and exercise intolerance.

For COPD patients, pulmonary rehabilitation significantly improves inspiratory muscle strength while decreasing the sensation of dyspnea. ${ }^{10}$ However, there has not been a developed standard method to evaluate the diaphragm movement in patients with COPD before and after pulmonary rehabilitation. Previous studies have reported methods to measure diaphragm motions under various radiologic techniques. Singh et $\mathrm{al}^{11}$ measured the volume displaced by diaphragm motion in healthy controls and patients with emphysema from two-dimensional chest radiograms. A three-dimensional diaphragm reconstruction imaging technique has been described using spiral computed tomography (CT), which allows an accurate measurement of diaphragm length and surface area. ${ }^{12}$ Dynamic magnetic resonance imaging (MRI) has been utilized to measure diaphragm and chest wall movement in control subjects and patients with emphysema. ${ }^{13}$ Although CT and MRI were used to measure the diaphragm movement in previous studies, these methods are costly and affect subjects with high radiation exposure. On the other hand, fluoroscopyguided imaging has benefits in terms of both cost and time savings, as well as lowering exposure to radiation hazard, compared with CT or MRI. In addition, fluoroscopy can provide a simple visual image that can be easily understood by patients, compared with CT, MRI, and ultrasonography. Therefore, fluoroscopic imaging may be useful to assess the effect of pulmonary rehabilitation in patients with stable COPD in view of accuracy and cost.

The aim of this study was to assess the effectiveness of fluoroscopic evaluation of the change of diaphragm volume before and after pulmonary rehabilitation training in patients with COPD.

\section{Materials and methods Patients}

Eighty participants failed to complete the 3-month pulmonary rehabilitation program due to the time requirements, expense and general weakness or symptom aggravation during the rehabilitation period. Therefore, only 37 patients who completed the 3-month pulmonary rehabilitation programs with both a fluoroscopy-guided chest X-ray and pulmonary function test were enrolled in this study. Exclusion criteria for pulmonary rehabilitation were as follows: poor health conditions that interfered with undergoing the rehabilitation process and comorbidities such as severe pulmonary hypertension, unstable angina, recent myocardial infarction, severe arthritis, severe osteoporosis, presenting cancer, and perioperative state. Each member of the study group had spirometric evidence of chronic airflow limitation (forced expiratory volume in 1 second $\left[\mathrm{FEV}_{1}\right]$ /forced vital capacity [FVC] $<70 \%$ of predicted) with a diagnosis of COPD according to the criteria of the Global Initiative for Chronic Obstructive Lung Disease. ${ }^{14}$ All were male and had stable hemodynamic conditions without other severe systemic diseases or arthritis. Thirty-two patients were ex-smokers and five patients were smoking at the time of implementation of the study. Enrolled patients fulfilled the criteria of regular monthly follow-up at the outpatient pulmonary clinic and follow-up at the rehabilitation clinic with all necessary investigations for the study. Regular long-acting bronchodilators and inhaled corticosteroids were also used when the patients had positive bronchodilator responses. The patients were observed for more than a 12-week run-in period, when their regular treatment was maintained, to verify stability in their clinical and functional status. Informed consent was received from all participants. This study was approved by the Institutional Review Board of the Ewha Womans University School of Medicine, Mokdong Hospital, Seoul, Republic of Korea (Approval No ECT 13-301-37).

\section{Study design and method}

\section{Pulmonary rehabilitation}

The entire group received respiratory rehabilitation training at the start of the study at the rehabilitation center of Ewha Womans University Medical Center, and its effectiveness was checked by the same physiatrist of the Department of Rehabilitation at each follow-up. Pulmonary rehabilitation training included programs recommended by the American Thoracic Society, such as diaphragmatic breathing, pursed lip breathing, home-based self-exercise such as straw blowing and upper extremity endurance training (an arm exercise lifting or stretching elastic bands) and lower extremity endurance training (stationary cycle exercise or ground-based walking), and strength training by weight 
lifting. ${ }^{15}$ Training instructions were administered by the same physiatrist in the Department of Rehabilitation, in order to avoid a discrepancy in the methods of measurement. All patients continued the same rehabilitation program at home regularly. Each procedure was done for more than 30 minutes ten times daily. Participants submitted their records of their home-based exercise at the time of their outpatient clinic visit. The record included daily exercise methods and frequencies.

\section{Pulmonary function tests}

All participants underwent pulmonary rehabilitation for at least 3 months and performed pulmonary function tests before and after the completion of treatment. Recorded spirometry results were based on the best result from three acceptable efforts. The results are presented as a percentage of the predicted value.

\section{Fluoroscopy-guided chest radiographs and analysis of diaphragms}

Patients underwent posteroanterior (PA) chest radiographs in a standing position, using fluoroscopy with Sonialvision $80_{\mathrm{R}}$ (Shimadzu, Kyoto, Japan) to measure the diaphragm change between full expiration and inspiration. The moving areas between diaphragm and base points of the axis and vertex were measured as a pixel number using PiVie STAR 5.0 (Infinitt, Seoul, Korea). Diaphragm motion was measured using a modified method described in Singh et al's ${ }^{11}$ study. Before and after pulmonary rehabilitation, all patients underwent fluoroscopic measurements of diaphragmatic movements on both sides under the guidance of the same physiatrist. The physiatrist measured the areas of maximal inspiration and expiration with a chest radiograph for each patient. To minimize radiation exposure, a fluoroscopic examination for inspiration and expiration was performed within 5 seconds per patient. The average time spent taking chest radiographs for both inspiration and expiration was also approximately 5 seconds. All patients underwent PA chest radiographs to estimate the change in diaphragm movement before and after pulmonary rehabilitation. The base points to measure the volume displaced by diaphragm motion are usually different based on the individual patient; thus, different base points were selected to minimize errors. Markers on the rib cage and the vertebral bodies from PA chest radiographs were used as base points to compare pre- and postdiaphragmatic movements. Patients were asked to breathe deeply, and fluoroscopies were performed while patients took a series of deep breaths. A chest radiograph was taken at the time of maximum inspiratory effort using guided fluoroscopy. Patients were then asked to exhale completely, and fluoroscopic measurements were repeated to take radiographs during full expiration. ${ }^{16}$

A schematic illustration was described by using chest radiographs through the following procedures. The origin of the diaphragm was identified at the costophrenic angle where the diaphragm peels away from the chest wall. The outline of the diaphragm dome was traced and, using a marking pen, a line was drawn along the silhouette on the radiograph. Vertebral columns located at the same level of costal insertion were identified, and transverse lines were drawn from the costal insertion of the diaphragm to the spinal process of vertebral columns (horizontal line). The area displaced by diaphragm motion was measured according to the area consisting of the vertical line of vertebral columns, the horizontal line, and the shadow of the diaphragm dome based on the PA chest radiograph (Figures 1 and 2). The time for fluoroscopy to measure the change of the diaphragm is relatively short; thus, radiation hazards to patients were minimized. The area of diaphragm displacement was calculated after both pre- and postpulmonary rehabilitation by the same physiatrist.

\section{Statistical analysis}

Pre- and postpulmonary functions were compared using a paired $t$-test. Descriptive frequencies were expressed as means \pm standard deviation. Areas of displacement of the right and left diaphragm measured pre- and postpulmonary rehabilitation, on inspiratory-expiratory motion under fluoroscopy, were compared using paired $t$-test. Pearson and Spearman correlation coefficient analysis was used to assess relationships between the changes of diaphragm and variables. A $P$-value less than 0.05 was considered statistically significant. Statistical analyses were performed with the use of SPSS 15.0.

\section{Results}

Table 1 presents subject characteristics of patients with COPD. All subjects were male and had a body mass index within the normal range. Thirty-two patients were exsmokers, while five were current smokers. The average duration for pulmonary rehabilitation was $6.7 \pm 2.8$ months. Table 2 shows the baseline data of arterial blood gas, echocardiography, and pulmonary function test in patients with COPD. All patients had evidence of moderate to severe airflow obstruction, with prerehabilitation FVC and 


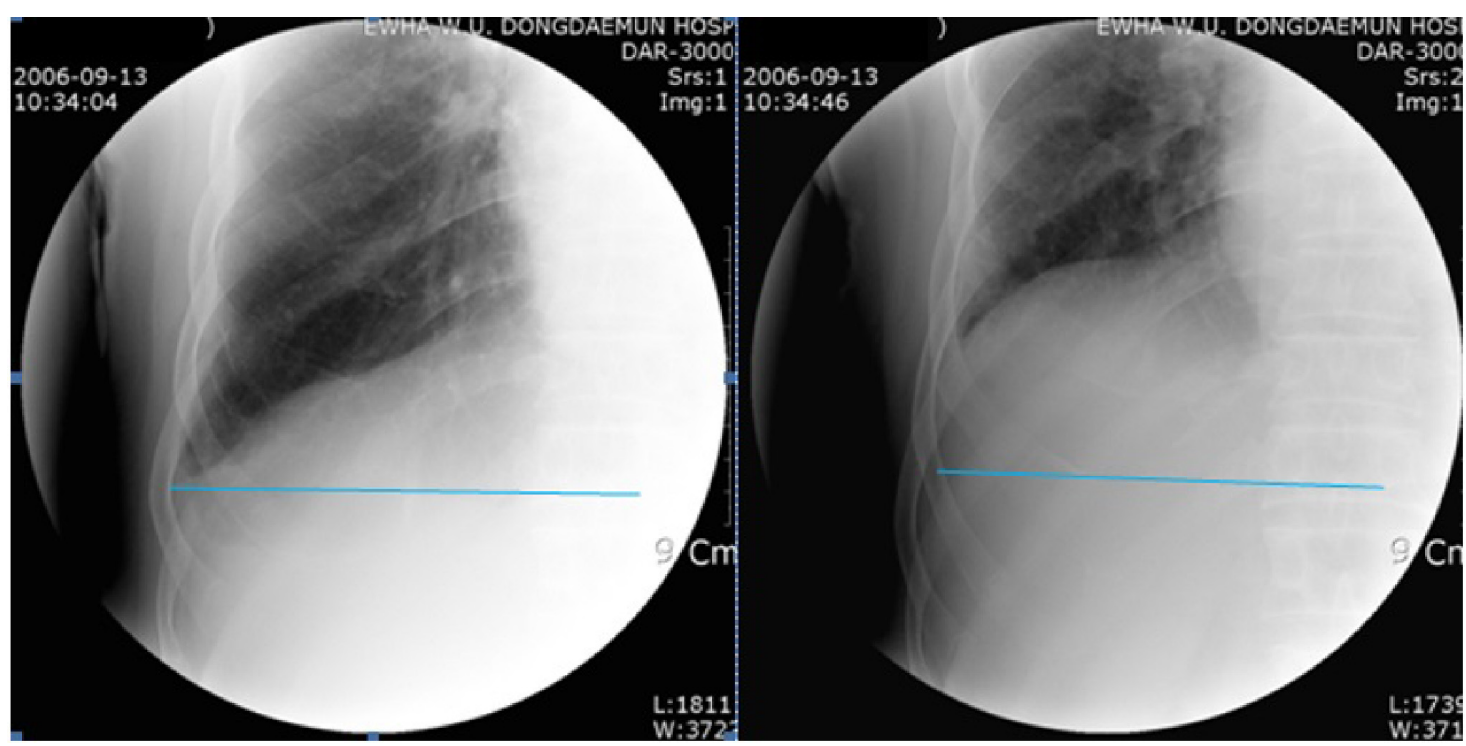

Figure I Radiographic image of the area displaced by diaphragm motion during inspiration and expiration for the same chronic obstructive pulmonary disease patient. Note: The thick horizontal lines of posteroanterior radiographs represent the costal insertion of diaphragm to the same spinal process of vertebral column between full inspiration and full expiration.

$\mathrm{FEV}_{1}$ percentages of $73.4 \% \pm 24.5 \%$ and $50.1 \% \pm 19.5 \%$, respectively. Cardiac ejection fraction percentage was $57.4 \% \pm 7.4 \%$. All of the basic blood test results were within the normal range.

\section{Pulmonary functions changes}

Table 3 exhibits changes in pulmonary functions in COPD patients between pre- and postpulmonary rehabilitation programs. The results indicate that there were no significant differences in $\mathrm{FVC}(\%)(P=0.137), \mathrm{FEV}_{1}(\%)(P=0.297)$, or forced expiratory flow at $25 \%-75 \%(\%)(P=0.921)$ in the subjects after the 3 months of pulmonary rehabilitation, compared with prerehabilitation.
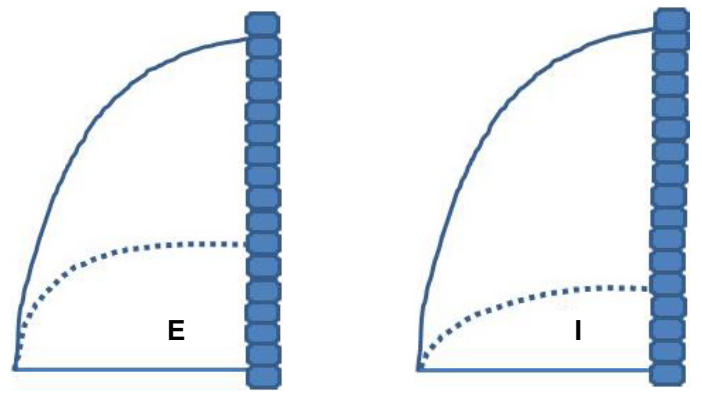

$$
\begin{aligned}
& \text { Diaphragmatic } \\
& \text { moving area }
\end{aligned}=\text { expiratory area }- \text { inspiratory area }(E-I)
$$

Figure 2 Schematic illustration of the area displaced by diaphragm movement during both inspiration (Area I) and expiration (Area E) in patients with chronic obstructive pulmonary disease.

Notes: Horizontal line shows low margin of vertebral body connecting the costal insertion of diaphragm. Vertical brick line shows thoracic vertebral spinous processes. Low curved thick line shows diaphragm shadow.

\section{Area change of diaphragm before and after pulmonary rehabilitation}

Table 4 shows values of expiratory-inspiratory diaphragm displacement of the right and left lung, before and after the pulmonary rehabilitation, measured under fluoroscopy. There were significant improvements in diaphragmatic movements on both right $(P=0.001)$ and left $(P=0.019)$ sides after the pulmonary rehabilitation program. There was no statistically significant difference between the changes of diaphragm and variables.

\section{Discussion}

Diaphragm weakness has been ascribed to hyperinflationinduced diaphragm shortening due to loss of muscle fibers. ${ }^{17}$ In emphysema, there is a loss of long sarcomeres and reduced diaphragm length, especially in the zone of apposition of

Table I Subject characteristics of chronic obstructive pulmonary disease patients $(\mathrm{N}=37)$

\begin{tabular}{ll}
\hline Age, years & $65.2 \pm 10.1$ \\
Sex (male:female) & $37: 0$ \\
Body mass index $\left(\mathrm{kg} / \mathrm{m}^{2}\right)$ & $21.7 \pm 2.9$ \\
Ex-smokers & 32 \\
Current smokers & 5 \\
$\quad$ Pack-year & $38.3 \pm 20.1$ \\
Exercise period (months) & $6.7 \pm 2.8$ \\
Comorbidities & \\
$\quad$ Cardiovascular & 19 \\
$\quad$ Others & 0 \\
\hline
\end{tabular}

Note: Values are expressed as mean \pm standard deviation. 
Table 2 Anthropometric and pulmonary function data $(n=37)$

\begin{tabular}{ll}
\hline Arterial blood gas analysis & \\
$\mathrm{PaO}_{2}(\mathrm{mmHg})$ & $75.7 \pm 10.9$ \\
$\mathrm{PaCO}_{2}(\mathrm{mmHg})$ & $45.6 \pm 7.8$ \\
Spirometry (pre) & \\
FVC/FEV \% predicted & $46.4 \pm 14.8$ \\
$\mathrm{FVC} \%$ predicted & $73.4 \pm 24.5$ \\
$\mathrm{FEV}, \%$ predicted & $50.1 \pm 19.5$ \\
$\mathrm{FEF}_{25 \%-75 \%} \%$ predicted & $23.7 \pm 16.0$ \\
GOLD stage (\%) & \\
GOLD I & 10.8 \\
GOLD II & 40.5 \\
GOLD III & 35.2 \\
GOLD IV & 13.5 \\
Echocardiography & \\
Ejection fraction (\%) & $57.4 \pm 7.4$ \\
RVSP (mmHg) & $40.4 \pm 23.2$ \\
\hline
\end{tabular}

Note: Values are expressed as mean \pm standard deviation.

Abbreviations: FVC, forced vital capacity; $\mathrm{FEV}_{1}$, forced expiratory volume in I second; $\mathrm{FEF}_{25 \%-75 \%}$, forced expiratory flow at $25 \%-75 \%$; GOLD, Global initiative for chronic Obstructive Lung Disease; RVSP, right ventricular systolic pressure; $\mathrm{PaCO}_{2}$, partial pressure of carbon dioxide; $\mathrm{PaO}_{2}$, partial pressure of oxygen.

diaphragm to the rib cage. ${ }^{18}$ Additionally, Ottenheijm et al ${ }^{19}$ postulated that oxidative stress and sarcomeric injury may lead to contractile protein wasting and, consequently, loss of force-generating capacity of diaphragm fibers in patients with COPD. Previous studies have proved that pulmonary rehabilitation markedly improved the strength of the inspiratory muscles in patients with COPD. Several imaging techniques have been tried to evaluate diaphragmatic motion after pulmonary rehabilitation. Therefore, in the present study, we concentrated on measuring diaphragm length to assess the benefits of pulmonary rehabilitation in the setting of fluoroscopy-guided imaging.

Singh et $\mathrm{al}^{11}$ measured diaphragm length and volume using PA and lateral radiography. Unal et $\mathrm{al}^{20}$ demonstrated that the decrease of the excursion of the diaphragm appeared to be proportional to the degree of airway obstruction, with a decrease in $\mathrm{FEV}_{1}$ with MR fluoroscopy in COPD patients. Three-dimensional reconstruction of the diaphragm using

Table 3 Results of pulmonary function test between pre- and postpulmonary rehabilitation in patients with chronic obstructive pulmonary disease $(n=37)$

\begin{tabular}{llll}
\hline & $\begin{array}{l}\text { Prepulmonary } \\
\text { rehabilitation }\end{array}$ & $\begin{array}{l}\text { Postpulmonary } \\
\text { rehabilitation }\end{array}$ & P-value* \\
\hline FVC (\%) pre- & $73.4 \pm 4.0$ & $77.4 \pm 3.6$ & 0.137 \\
FEV $_{1}(\%)$ pre- & $50.1 \pm 3.2$ & $51.9 \pm 4.2$ & 0.297 \\
FEF $_{25 \%-75 \%}(\%)$ & $23.7 \pm 2.7$ & $23.8 \pm 3.4$ & 0.921 \\
\hline
\end{tabular}

Notes: Values are expressed as mean \pm standard error. Significant difference between pre- and postpulmonary rehabilitation: $* p<0.05$ (paired $t$-test).

Abbreviations: FVC, forced vital capacity; $\mathrm{FEV}_{1}$, forced expiratory volume in I second; $\mathrm{FEF}_{25 \%-75 \%}$, forced expiratory flow at $25 \%-75 \%$.
Table 4 Changes of diaphragmatic area between expiratoryinspiratory diaphragm motion with fluoroscopy in patients with chronic obstructive pulmonary disease $(n=37)$

\begin{tabular}{llll}
\hline & $\begin{array}{l}\text { Prepulmonary } \\
\text { rehabilitation }\end{array}$ & $\begin{array}{l}\text { Postpulmonary } \\
\text { rehabilitation }\end{array}$ & P-value* \\
\hline Right $\left(\mathrm{mm}^{2}\right)$ & $2,022.8 \pm \mathrm{I}, 548.3$ & $3,010.7 \pm \mathrm{I}, 495.6$ & $0.00 \mathrm{I}$ \\
Left $\left(\mathrm{mm}^{2}\right)$ & $2,382.4 \pm \mathrm{I}, 475.9$ & $3,315.9 \pm \mathrm{I}, 883.5$ & 0.019 \\
\hline
\end{tabular}

Notes: Values are expressed as mean \pm standard deviation. Significant difference between pre- and postpulmonary rehabilitation: $* P<0.05$ (paired $t$-test).

a spiral CT scan allows accurate measurements of muscle length, surface area, and shape of the diaphragm. ${ }^{21}$ However, there is only a minor difference in accuracy between measurements done by chest radiographs, CT scan, ${ }^{22}$ and MRI. ${ }^{23}$ In addition, there is always a high risk of radiation hazard using a CT scan, while MRI investigations are expensive. Smargiassi et $\mathrm{al}^{24}$ showed that ultrasonographic evaluation of the diaphragm in COPD patients demonstrated disease progression in terms of lung hyperinflation and the loss of fat-free mass. Ultrasonography is useful in children for the evaluation of diaphragm structure and function because of there being no risk of radiation and mobility. ${ }^{25}$ Nevertheless, the accuracy of ultrasonographic imaging has been criticized for being examiner dependent. Additionally, the accuracy is also determined by the condition of patients. Summerhill et $\mathrm{al}^{26}$ stated that fluoroscopy was not an ideal strategy for critically ill patients because patients are required to breathe spontaneously during fluoroscopy. The aim of the present study was to evaluate the diaphragm improvement after pulmonary rehabilitation in stable COPD patients. Therefore, fluoroscopy is less expensive and more objectively accurate than ultrasonography in evaluation after pulmonary rehabilitation in patients with COPD.

Kleinman et $\mathrm{al}^{27}$ used fluoroscopy to compare diaphragmatic excursion during spontaneous ventilation and positive pressure ventilation in patients with COPD and normal controls after anesthesia and neuromuscular blockade. They showed that there was no significant difference in the pattern of regional diaphragmatic excursion between the two groups. In the present study, PA chest radiographs were performed under fluoroscopy image to measure the diaphragm length and volume change in patients with COPD. There have been various published methods to measure the diaphragm length. In a study by Bellemare et $\mathrm{al}^{28}$ anatomic landmarks were used to estimate the length of the diaphragm from chest radiographs to evaluate the functional capacity of diaphragm in patients who were candidates for lung volume reduction surgery. In this study, the authors found that anatomic landmarks were not different between male and 
female participants of both normal subjects and emphysematous patients. Although each patient in the present study had a different landmark, the areas of maximal inspiration and expiration were measured as the same point in each patient during fluoroscopy imaging, so the methodological problems for anatomic landmarks could be overcome. With fluoroscopy, the dome of diaphragm movement could be effectively seen, as well as measurement of the change in area due to movement of diaphragm. To minimize the risk of radiation for subjects, the procedure was performed within 5 seconds of exposure to radiation. Physicians can show the visual improvement of diaphragm to COPD patients based on a simple radiographic imaging. COPD patients may be encouraged to continue pulmonary rehabilitations through the real visual chest image; therefore, fluoroscopic imaging can be used as an effective and cost-saving tool in evaluating pulmonary rehabilitation in the clinical field.

In the present study, there was significant improvement of diaphragmatic motion area in both sides after respiratory muscle training, although pre- and postpulmonary function tests were not changed. Although the fluoroscopy-guided measurement is a relatively effective tool to assess the change of diaphragm area after pulmonary rehabilitation, our study had several limitations. First, the moving area of the diaphragm was not assessed using a three-dimensional method; however, the accuracy of the posteroanterior silhouette on a plain radiograph was similar to the results derived from three-dimensional CT reconstructions. ${ }^{21}$ Second, no control group was used in the present study, and it also lacked randomization. This study targeted only moderate to severe COPD patients who required fluoroscopy. Therefore, it was difficult to make use of a normal control group and randomization because of the small number of COPD patients and the ethical problem of unnecessary radiation hazards to healthy subjects. Third, there were no long-term follow-up data for pulmonary rehabilitation. The positive effects of pulmonary rehabilitation have been observed for between 12 weeks and 24 weeks in patients with COPD. These positive effects included improvements in quality of life, perception of dyspnea, and physical performance. ${ }^{29}$ One year of outpatient multidisciplinary pulmonary rehabilitation resulted in greater walking ability and also decreased use of health-related services in patients with COPD than in the control group. ${ }^{30,31}$ Previous research has demonstrated that the effect of pulmonary rehabilitation generally appears after 12 weeks; therefore, the duration of training in the present study would be appropriate to achieve the effect of rehabilitation. Fourth, the participants were all male patients. The smoking rate among Korean females is relatively very low, accounting for approximately less than $3 \%$, and the incidence of female COPD patients is very low compared with the total number of COPD incidents. Therefore, this present study enrolled a relatively small number of COPD patients, and all participants were male patients.

\section{Conclusion}

To our knowledge at present, there are few available reports on the effectiveness of fluoroscopy to measure diaphragm activation and length in patients with COPD. We suggest that the analysis of the diaphragm area using fluoroscopy for the evaluation of pulmonary rehabilitation in patients with COPD is an effective technique compared with CT or MRI in terms of cost and radiation hazard. We can easily apply and reproduce this method, which can demonstrate to patients the improvement of the diaphragm with a simple visual image, to assess the change of diaphragm area after pulmonary rehabilitation in patients with COPD. However, a further study is needed to evaluate the optimal effectiveness of this method, incorporating a larger series of long-term follow-up data and using control patients.

\section{Acknowledgment}

The authors would like to thank staff at the Department of Rehabilitation for their efforts dedicated to patients with COPD involved this study.

\section{Disclosure}

The authors report no conflicts of interest in this work.

\section{References}

1. World Health Organization. The world health report 2002 - Reducing Risks, Promoting Healthy Life. Geneva: World Health Organization; 2002. Available from: http://www.who.int/whr/2002. Accessed January 6, 2015.

2. Lopez AD, Shibuya K, Rao C, et al. Chronic obstructive pulmonary disease: current burden and future projections. Eur Respir $J$. 2008;27:397-412.

3. Sharp JT, Danon J, Druz WS, Goldberg NB, Fishman H, Machnach W. Respiratory muscle function in patients with chronic obstructive pulmonary disease: its relationship to disability and to respiratory therapy. $\mathrm{Am}$ Rev Respir Dis Dec. 1974;110(6 Pt 2):154-168.

4. Nici L, Donner C, Wouters E, et al. American Thoracic Society/European Respiratory Society statement on pulmonary rehabilitation. Am J Respir Crit Care. 2006;173(2):1390-1413.

5. Laghi F, Tobin MJ. Disorders of respiratory muscles. Am J Respir Crit Care Med. 2003;168:10-48.

6. Orozco-Levi M, Gea J, Lloreta JL, et al. Subcellular adaptation of the human diaphragm in chronic obstructive pulmonary disease. Eur Respir J. 1999; 13:371-378.

7. Rochester DF, Braun NMT. Determinants of maximal inspiratory pressure in chronic obstructive pulmonary disease. Am Rev Respir Dis. 1985; 132:42-47. 
8. Levine S, Kaiser L, Leferovich J, Tikunov B. Cellular adaptations in the diaphragm in chronic obstructive pulmonary disease. $N$ Engl J Med. 1997:337:1799-1806.

9. Ottenheijm CAC, Heunks LMA, Sieck GC, et al. Diaphragm dysfunction in chronic obstructive pulmonary disease. Am J Respir Crit Care Med. 2005;172:200-205.

10. Lötters F, van Tol B, Kwakkel G, Gosselink R. Effects of controlled inspiratory muscle training in patients with COPD: a meta-analysis. Eur Respir J. 2002;20(3):570-576.

11. Singh B, Eastwood PR, Finucane KE. Volume displaced by diaphragm motion in emphysema. J Appl Physiol. 2001;91:1913-1923.

12. Pettiaux N, Cassart M, Paiva M, Estenne M. Three-dimensional reconstruction of human diaphragm using spiral computed tomography. J Appl Physiol. 1997;82:998-1002.

13. Mckenzie DK, Gorman RB, Tolman J, Pride NB, Gandevia SC. Estimation of diaphragm length in patients with severe chronic obstructive pulmonary disease. Respir Physiol. 2000;123:225-234.

14. Rabe KF, Hurd S, Anzueto A, et al. Global strategy for the diagnosis, management, and prevention of chronic obstructive pulmonary disease: GOLD executive summary. Am JRespir Crit Care Med. 2007;15:176(6): 532-555.

15. American Thoracic Society. Pulmonary Rehabilitaiton-1999. Am J Respir Crit Care Med. 1999;159(5 Pt 1):1666-1682.

16. Gorman RB, Mckenzie DK, Pride NB, Tolman JF, Gandevia SC. Diaphragm length during tidal breathing in patients with chronic obstructive pulmonary disease. Am J Respir Crit Care Med. 2002;166(11): 1461-1469.

17. Similowski T, Yan S, Gauthier AP, Mackle PT, Bellemare F. Contractile properties of the human diaphragm during chronic hyperinflation. N Engl J Med. 1991;25:917-923.

18. Thomas AJ, Supinski GS, Kelsen SG. Changes in chest wall structure and elasticity in elastase-induced emphysema. J Appl Physiol. 1986;61: 1821-1829.

19. Ottenheijm CAC, Heunks LMA, Dekhuijzen RPN. Diaphragm adaptations in patients with COPD. Respir Res. 2008;9:12.

20. Unal O, Arslan H, Uzun K, Ozbay B, Emin M, Sakarya ME. Evaluation of diaphragmatic movement with MR fluoroscopy in chronic obstructive pulmonary disease. Clin Imaging. 2000;24:347-350.
21. Cassart M, Pettiaux N, Gevenois PA, Pavia M, Estenne M. Effect of chronic hyperinflation on diaphragm length and surface area. Am J Repir Crit Care Med. 1997;156:504-508.

22. Pettiaux N, Cassart M, Paiva M, Estenne M. Three-dimensional reconstruction of human diaphragm with the use of spiral computed tomography. J Appl Physiol. 1997;82:998-1002.

23. Gauthier AP, Verbanck S, Estenne M, Segebarth C, Macklem PT, Paiva M. Three-dimensional reconstruction of the in vivo human diaphragm shape at different lung volumes. J Appl Physiol. 1994;76:495-496.

24. Smargiassi A, Inchingolo R, Tagliaboschi L, Di Marco Berardino A, Valentes S, Corbo GM. Ultrasonographic assessment of the diaphragm in chronic obstructive pulmonary disease patients: relationships with pulmonary function and the influence of body composition-a pilot study. Respiration. 2014;87(15):364-371.

25. Epelman M, Navarro OM, Daneman A, Miller SF. M-mode sonography of diaphragmatic motion: description of technique and experience in 278 pediatric patients. Pediatr Radio. 2005;35(7):661-667.

26. Summerhill EM, El-Sameed YA, Glidden TJ, McCool FD. Monitoring recovery from diaphragm paralysis with ultrasonography. Chest. 2008; 733(3):737-743

27. Kleinman BS, Frey K, VanDrunen M, Sheikh T, Dipinto D, Mason R, Smith T. Motion of the diaphragm in patients with chronic obstructive pulmonary disease while spontaneously breathing versus during positive pressure breathing after anesthesia and neuromuscular blockade. Anesthesiology. 2002;97:298-305.

28. Bellemare F, Couture J, Cordeau MP, Leblanc P, Lafontaine E. Anatomic landmarks to estimate the length of the diaphragm from chest radiographs: effects of emphysema and lung volume reduction surgery. Chest. 2001;120(2):444-452.

29. Verrill D, Barton C, Beasley BS, Lippard M. The effects of short-term and long-term pulmonary rehabilitation on functional capacity, perceived dyspnea, and quality of life. Chest. 2005;128(2):673-682.

30. Griffiths TL, Burr ML, Campbell IA, et al. Results at 1 year of outpatient multidisciplinary pulmonary rehabilitation: a randomised controlled trial. Lancet. 2000;355:362-368.

31. Downey A, Chenoweth L, Townsend D, Ranum J, Ferguson C, Harms C. Effects of inspiratory muscle training on exercise response in normoxia and hypoxia. Respir Physiol Neurobiol. 2007;156:137-146.
International Journal of COPD

\section{Publish your work in this journal}

The International Journal of COPD is an international, peer-reviewed journal of therapeutics and pharmacology focusing on concise rapid reporting of clinical studies and reviews in COPD. Special focus is given to the pathophysiological processes underlying the disease, intervention programs, patient focused education, and self management protocols.

\section{Dovepress}

This journal is indexed on PubMed Central, MedLine and CAS. The manuscript management system is completely online and includes a very quick and fair peer-review system, which is all easy to use. Visit http://www.dovepress.com/testimonials.php to read real quotes from published authors. 